\section{Language and gender: A critical discourse analysis on gender representation in a series of international ELT textbooks}

Amerian, Majid

Arak University, Iran (amerian1383@yahoo.com)

Esmaili, Fateme

ArakUniversity, Iran (fattimahesmailly7@gmail.com)

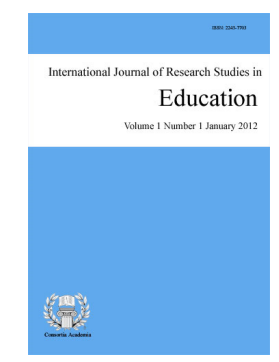

ISSN: 2243-7703 Online ISSN: 2243-7711

OPEN ACCESS

\title{
Abstract
}

This study attempted to explore the representation of gender in an international ELT series, i.e., American Headway Student Textbooks. Fairclough's (2001) three-dimensional model was selected and adopted as the model of study. Effectively, different parts of American Headway Student Textbooks were investigated systematically vis-à-vis eight factors, i.e. female and male's characters, female and male's social roles, female and male's domestic roles, female and male's semantic roles, female and male's titles, order of appearance, masculine generic construction, activities females and males engaged in, and finally the pictorial representation of both genders. The findings of the study revealed that the series are suffering from two types of sexism-overt and covert ones - the overt one discriminates against females in a vivid way and the covert one exploits the women as an instrument for advertising in order to promote selling. This study suggests that the series are instilling capitalism economy as ideology.

Keywords: gender representation; sexism; capitalism; covert sexism; overt sexism; critical discourse analysis 


\section{Language and gender: A critical discourse analysis on gender representation in a series of international ELT textbooks}

\section{Introduction}

Critical discourse analysis is a discipline that uncovers both the hidden and transparent social as well as political norms and values. CDA, as an interdisciplinary method, explores social and political context in order to emancipate ideologies, hegemony, dominance and social powers (Fairclough, 2001). CDA as a multifunctional approach has different applications within different domains; and education is one of these domains. One of the interesting applications of CDA which has attracted the attention of many researchers in the domain of education is textbooks in general and ELT materials in particular. Effectively, textbooks can be investigated from diverse points of view, for example, gender representation, ethnicity, cultural factors.

Designing and developing any textbook and especially the ELT textbooks demands considering a vast variety of factors, for example, age, ethnicity, class, gender, ability levels, or purposes of the curriculum. There is no doubt that examining any textbook may reveal the pattern through which the content of the textbooks were being included or even excluded regarding any particular factor.

One of the issues, recently provoked much debate in educational system is the issue of gender bias in ELT materials. Gershuny (1977) argues that the textbooks are supposed to instruct some disciplines, but these textbooks, in effect, convey secondary information that is "gender roles and social values" (p. 150). Consequently, textbooks, not only instruct some information; but they also play a crucial role in transmitting gender roles and social values to students. Accordingly, evaluating ELT materials is crucial for both teachers and learners in terms of the insight the gender-based studies provide for them. Furthermore, exploring the ELT textbooks in terms of gender equips the learners with the critical outlook.

The aforementioned issues were some incentives to explore one of the international series of ELT textbooks, which are exposed to many language learners in the context of Iran, namely, American Headway series. In effect, the series were investigated regarding gender representation by applying Fairclough's (2001) three- dimensional model. To this end, eight factors were investigated in the series in order to demystify the ideology behind the series regarding gender. Hence, the extracted data were analyzed to determine the role played by gender. Furthermore, this study attempted to find out whether or not the presentation of females and males follow any specific ideological pattern of manipulation along with its due features.

\section{Background Knowledge}

The literature review is divided into three sections. The first focuses on CDA, the second on language and gender and the third section on some cases of the empirical studies.

\subsection{Critical Discourse Analysis}

Critical discourse analysis (CDA) is a discipline, which investigates "the power relations, ideological manipulations, and hegemony" (Rahimi \& Sahragard, 2007, p. 1). CDA indicates what has formerly been known as critical linguistics (CL) (Wodak, 2002) which was emerged in the late 1970s (Fowler \& Kress, 1979). CDA, in effect, deals with both "opaque and transparent structural relationships of dominance, discrimination, power and control” (Wodak, 2007, pp. 208-209). CDA, in Wodak's (2001) prospect, emphasizes on "language as social practice" (p. 1), by considering the contextual factors (Weiss \& Wodak, 2003).

Norman Fairclough is one of the most influential researchers in the domain of CDA taking a specific middle range theory based on Halliday's systemic functional linguistics theory which denotes a "pragmatic, 
problem-oriented approach" (Meyer, 2001, p. 28). Fairclough emphasizes on "social conflict in the Marxist tradition and tries to detect its linguistic manifestations in discourse in particular elements of dominance, difference and resistance" (cited in Meyer, 2001, p. 22). Fairclough (2001) calls his particular method critical language study $(C L S)$ and depicts it as "a contribution to the general rising of consciousness of exploitive social relations, through focusing upon language" (p. 4).

Fairclough's (2001) three-dimensional model is one of main approaches utilized in exploring gender representation in the EFL textbooks. In analyzing any communicative event, CLS considers three simultaneous focuses: text, discourse practice and socio-cultural practice (Chouliaraki \& Fairclough, 1999). Fairclough (1989) assumes power, ideology and language as a unitary system. He states that "the gist of my position is that language connects with the social through being the primary domain of ideology, and through being a sit of, and a stake in, struggles of power" (Fairclough, 1989, pp. 14-15).

\subsection{Language and Gender}

Attention to the relationships between language and gender as a domain of study emerged during the 1960s and 1970s with three books: Male/Female Language (Key, 1975), Language and Women's Place (Lakoff, 1975), and Difference and Dominance (Thorne \& Henley, 1975). Gender is a contextual-dependent concept that contributes various linguistic strategies to males and females (Bell, McCarthy \& McNamara, 2006). Gender depicts the roles of women and men established by the society. Each society has a particular point of view towards the roles played by women and men and has specific expectations from them (Bell, McCarthy, \& McNamara, 2006). These expectations depend on cultural, political, economic, social and religious factors (Bell et al., 2006). Customs, law, class, ethnic background, as well as prejudices of a particular society have a certain disposition towards women and men; and these issues construct particular attitudes and behaviors towards gender. It is culturally assumed that females and males constitute two extremes of traits. In fact, females occupy suppressed groups that incarnate negative characteristics as passiveness, weakness, dependence, and emotionality; males comprise the dominant groups with the positive characteristics such as strangeness, activity, independence, and rationality (Ho, 2009). It is apparent that these tags to females and males are not natural and inherent, but are socially and culturally constructed and supported.

\subsection{Empirical Studies on Gender Representation in Textbooks}

Tahriri and Moradpour (2014) studied the Top Notch Series in terms of gender representation utilizing a Critical Discourse Analysis model. To this end, they analyzed the series on three major aspects of gender, i.e. relations, positions, and content based on Fairclough's (2001) three-dimensional model. They found that the both genders are represented almost equally. Their study also showed that the series has resorted to the capitalism ideology in depicting gender. Keshavarz and Malek (2009), in a similar vein, investigated gender representation in the ILI (Iran Language Institute) and True to Life textbooks in terms of social relations, subject positions and contents. Their study showed that these two groups of textbooks are composed of equal social status between participants. In addition, friends, occupational and commercial positions are dominant themes in these two series. Moreover, market issue —one representation of western economy and capitalism—is emphasized in the both series. Stockdale (2006) evaluated Impact Values series in terms of gender representation. To this end, he investigated this series in terms of gender bias-related issues including visibility, firstness, nouns and pronouns as well as discourse roles. His study showed that the series displayed significant bias favoring to males.

\section{Methodology}

This study tried to investigate an international ELT textbooks series, i.e. American Headway Student's Textbooks, utilizing a critical discourse analysis approach. It is worth mentioning that the present study innovatively merged the principles of the critical discourse analysis and the gender studies in order to provide more dependable results. 


\subsection{Data Selection and Sampling}

American Headway Student's Textbooks were chosen randomly from among eight other popular ELT textbooks currently being taught in Iran. The American Headway Series are multiple skills general English textbooks published by Oxford University Press and released in 2001. The American Headway series includes three groups of student's book, teacher's book and workbook, each with five volumes. Three volumes of American Headway Student Textbooks were selected as the corpus of the present study.

\subsection{Methodological Framework}

It was previously emphasized that Fairclough's (2001) three-dimensional model was selected and adopted in conducting the study to explore gender representation in the series and tried to demystify the ideology behind the way through which gender is depicted. Fairclough (2001) numerates three types of constraints which are deployed by the elites over the contributions of non-powerful participants, "constraints on contents, relations and subjects" (Fairclough, 2001, p. 61). Fairclough (2001) emphasizes that all the three constraints are in either "relatively immediate and concrete terms or in a relatively structural and long term way (p. 61). It is worth mentioning that the power behind the discourse which has "long term structural effects of a more general sort" (Fairclough, 2001, p. 61) was the focus of the present study.

Fairclough (2001) points out that "achieving coordination and commonality of practice in respect of knowledge and beliefs, social relationships, and social identities" (p. 62) demands a number of mechanisms which differs from one society to another. He categorizes these mechanisms in three classes of the practices and discourse types which are followed universally, the "inculcation" ones and the "communication" mechanisms (Fairclough, 2001, p. 62). For the purpose of the present study, the mechanisms which are "imposed in the exercise of power in a largely hidden fashion" (Fairclough, 2001, p. 62) were addressed and explored.

\subsection{Procedure}

The main purpose of the present study was to detect the ideologies behind an international English series. To this end, the following issues were analyzed:

$>\quad$ The ratio of the frequency of females to males and the similarities or differences between them;

$>\quad$ The female and male's social as well as domestic roles and the similarities or differences between them;

$>\quad$ The female and male's semantic roles and the similarities or differences between them;

$>\quad$ The female and male's titles and the similarities or differences between them;

$>\quad$ The female and male's order of appearance and the similarities or differences between them;

$>\quad$ The female and male's pictorial representations and the similarities or differences between them;

$>\quad$ The masculine generic construction and similarities or differences between them;

$>$ Activities females and males attended and similarities or differences between them;

In fact, the above factors were investigated to detect the ideology based on which the presentation of gender is manipulated.

\section{Results and Discussion}

One of the issues that this paper analyzed in order to detect gender bias was omission-a concept which 
refers to including one gender and excluding the other. As far as the review of literature is concerned exclusion of one gender in the materials which are presented to the students influences the excluded gender negatively. It means that, representing one gender less than the other one implies that the excluded gender and his/her behaviors are not worthy to be considered. The issue should not be neglected that sex-bias representation in the textbooks impacts the learning potentials of the students in a negative way in which not only the excluded ones but also the dominated gender is affected and can't realize their full potentials. Analyzing American Headway Students textbooks resulted into the supremacy of males over females. In fact, 2041 cases out of 3352 cases presented males in forms of proper nouns, pronouns, or other representations; whereas, the portion of females were 1311 cases. Hence, $61 \%$ of the cases represented the males; while only $39 \%$ of the cases depicted the females. Considering the aforementioned percentages denotes that males have allocated nearly more than two in three of representation of gender to themselves.

The next factor which was investigated in conducting the present study was sex stereotypes. Sex stereotype is a concept, which refers to the roles considered suitable for a gender in each society. In investigating this part of study we, in a similar direction with Esmaili and Amerian (2013) considered five categories of male-monopolized (performed by men only), male-dominated (largely performed by men), female-monopolized (performed by women only), female-dominated (largely performed by women) and gender-shared (performed by both gender equally).

Table 1 shows that this series did biasedly in representing the social roles dedicated to females and males. In other words, in most social roles presented in these textbooks males won the competition and were dominant. It should be mentioned that the social roles considered appropriate for males as monopolized or dominated have a higher social positions compared to the ones considered for females. The table shows that $49 \%$ of the social roles which were depicted in American Headway Students' Textbooks are male-monopolized; while this number was $26 \%$ for female-monopolized social roles. Furthermore, it was found that $10 \%$ and $3 \%$ were displayed as dominated by males and females respectively. This point is worth mentioning that only $12 \%$ of social roles were equally shared between the two genders.

\section{Table 1}

The Social Roles of each Gender in American Headway Student Textbooks

\begin{tabular}{lc}
\hline \multicolumn{1}{c}{ Social Roles } & Percentages \\
\hline Types of social roles & Percent \\
Male-monopolized social roles & $49 \%$ \\
Male-dominated social roles & $10 \%$ \\
Female-monopolized social roles & $26 \%$ \\
Female-dominated social roles & $3 \%$ \\
Gender shared social roles & $12 \%$ \\
\hline
\end{tabular}

The third issue undertaken by the study was exploring the semantic roles which were played by females and males in the reading section of the series. Effectively, five semantic roles of actor, patient, recipient, experiencer and beneficiary were investigated in the reading parts of the series. Investigating this issue as the previous ones showed the domination of the male characters. In effect, the results of investigating social roles revealed that $69 \%$ of the cases were related to males and $31 \%$ to females in which men enjoys from $27 \%$ as actor roles, $4 \%$ of patient roles, $34 \%$ of experiencer roles and $1 \%$ of beneficiary roles. Furthermore, women's share of the social roles composed of $14 \%$ for actor roles, $6 \%$ for patient roles, $6 \%$ for experiencer roles, $5 \%$ for beneficiary and $0 \%$ of recipient roles.

Title is another factor, which denotes gender biases. English is a language in which differences between females and males are heightened utilizing titles in which the marital status of the females are emphasized. English language in addressing females utilizes a number of titles, i.e. Miss, Mrs., and Ms.. In the American Headway Student textbooks, different types of the titles were presented with unequal distribution. Statistically, the title of Mr. had the most frequent distribution with $75 \%$ of the cases. Other titles had the distribution of $15 \%$ 
Amerian, M., \& Esmaili, F.

for Mrs. 6\% for Miss and 3\% for Ms.

"Order of appearance" as another manifestation of gender representation was also investigated which refers to the order through which each gender is represented (whether the first or the second position). Exploring American Headway Series in terms of the order of appearance-whether females were presented at the first position or at the second-revealed the triumph of females. Whereas, in the $75 \%$ of cases females were depicted in the first position; only in the $25 \%$ of the cases males were represented in the first position.

Masculine generic construction is another sex-bias' concept which means using the masculine nouns or pronouns in addressing both genders. Investigating this issue resulted in some cases of using man, mankind, boy, him and he in referring to both genders in general which is suggesting some degree of sex bias. Furthermore, the activities each gender engaged in were investigated in order to reveal any trace of sex bias in order to provide some bases for teaching. The activities in these textbooks were summarized in Table 2. The table indicates that the range of presented activities as appropriate for females or males is relatively diverse.

However, the American Headway Series has depicted the women in relatively diverse activities; the activities women engaged in seem to have lower positions compared with those of men. Hence, there were some activities that were dominated by a gender. In the investigated series, most of activities were dominated in favor of one gender-in most cases, these were women who pay for this privilege. Hence, it seems that there is a vast drift between the activities performed by females and males in such a way that most activities were dominated by males, for example, "driving, eating in restaurant", "working” or "going to work", "studying or going to school/college/university", "playing”, "watching TV or movies”, "engaging in social activities”, "doing/participating/going to sport", and "engaging in "personal activities". On the other hand, "making/going to party", "shopping", "traveling" and "housework" were the only activities dominated by females. Moreover, "going on vocation", and "engaging in personal activities" were the activities equally shared by the two genders. It was found that there is notorious imbalance in the activities ascribed to females or males.

\section{Table 2}

Activities in American Headway Student Textbooks

\begin{tabular}{lcc} 
& \multicolumn{1}{c}{ Activities } & Fotal \\
\hline Kinds of activities & Female & male \\
Making party/going to party & 19 & 6 \\
driving & 5 & 20 \\
shopping & 10 & 2 \\
Going vocations & 14 & 14 \\
Eating in restaurant & 3 & 7 \\
Work & 49 & 92 \\
Studying/ at school & 16 & 19 \\
Playing & 7 & 22 \\
Watch TV & 8 & 9 \\
Engaging in social activities & 6 & 15 \\
Doing sport & 0 & 24 \\
Engaging in personal activities & 18 & 20 \\
travelling & 14 & 8 \\
housework & 20 & 2 \\
total & $42 \%$ & $58 \%$ \\
\hline
\end{tabular}

Apparently, a specific pattern has directed the activities, which were contributed to each gender. Analyzing the activities which were attributed to each gender showed that the positive and active roles and activities are mainly ascribed to men; and the passive and negative activities to women. This particular representation of activities sheds light on another trace of sex bias.

The last issue which was investigated in American Headway Student Textbooks was pictorial representation of genders. Table 3 deals with pictorial representation in American Headway Series. American Headway Student 
Books contain 443 pictures relating to gender, out of which, 153, 31, 108, 13, and 108 cases manifest "male only", "male and females with the supremacy of males", "females only", "male and females with the supremacy of females" and "equal sharing between females and males". Furthermore, 30 cases were not recognized whether they represented females or males.

Table 3

Pictorial Representation in American Headway Student's Textbooks

\begin{tabular}{lc}
\hline \multicolumn{1}{c}{ Pictorial representation } & American Headway Students' Textbooks \\
\hline Male only & $153(34.5 \%)$ \\
More males & $31(7 \%)$ \\
Females only & $108(24 \%)$ \\
More females & $13(2.9 \%)$ \\
Equal share & $108(24 \%)$ \\
Not-recognized & $30(6.7 \%)$ \\
Total & $443(100 \%)$ \\
\hline
\end{tabular}

As the table shows, nearly $35 \%$ of pictures have presented male-only and $24 \%$ female-only. In addition, $24 \%$ of these pictures represented the equal sharing between females and males. Furthermore, $7 \%$ and $3 \%$ of the pictures showed the mixed gender when the males outnumbered and also when the females outnumbered, respectively. In a nutshell, the achieved findings stress on the inequality between female and male. In the American Headway Series (Student Book 2, 3 and 4), most pictures have presented the issue of gender with market-related issues as Nestle KitKat, Starbucks Coffee, Cannons Health Club, AAA Insurance Agency, B \& B Vacancies, A-1 Self Storage, American Liberty Mortgage \& Loan Corporation, Rocky's Ace Hardware, Fender Menders, Coca-Cola, McDonald's Hamburgers, a few among others.

Hence, investigating the eight gender-related items in American Headway Student Textbooks resulted in the gender discrimination. In effect, $39 \%$ of the characters in the series was devoted to females; whereas the males have allocated $61 \%$ of the cases to themselves. Lee (2006) emphasizes that under-representing females implicitly expresses that females and their accomplishments are not worthy. As other investigated textbooks over the world, in this case, females seem to be treated unfairly in such a way that their portion to males is about 1 to 2 . In other words, males are represented nearly twofold comparing females. In addition, investigating the social roles presented in the series showed that $10 \%$ of the cases were monopolized by men and $3 \%$ by women. Furthermore, $49 \%$ of social roles were dominated by men and $26 \%$ by women. $12 \%$ is the portion of the gender-sharing social roles. It means that the two genders had equal chances only in $12 \%$ of social roles. Exploring the domestic roles showed another traces of sexism in which the share of males was about 52\% and the share of females about $48 \%$. Investigating the semantic roles ascribed to each gender revealed that females occupied $32 \%$ and males $68 \%$. It means that the males outnumbered more than twofold comparing females. Hence, prejudices against women permeated through these textbooks.

Hence, the issue of sexism seems to be deep-rooted. Investigating the factor of titles as another manifestation of gender bias clarified the significant role the marital status of women plays in addressing a female whereas there is not such a situation about males. Investigating order of appearance resulted in an opposite direction in which these were the women who were outnumbered. However, the females were represented as the first interlocutor in about $75 \%$ of the cases; the women were depicted as the first interlocutor who played a minor role. Even this investigation upholds existence of sexism in these textbooks and it is not a point that was performed accidentally or sporadically but this kind of presenting females and males is a pre-determined and pre-programmed process that pursues a specific purpose.

Moreover, investigating other factors-masculine generic construction, activities or pictorial representation - not only shows biases towards females but also indicates that the series have ignored them easily. It is worth mentioning that the manner in portraying both genders seems to be systematic and follows a specific direction in order to instill particular perspective and ideology. Furthermore, investigating the pictorial 
representation showed that most of the pictures portrayed both genders especially females in association with some market-related materials or along with some trademarks. It seems that the designers of these textbooks along with many other EFL textbooks' designers view women as some instruments to advertise their materials and by which extend their sales by absorbing more and newer customers. This kind of direction towards gender confirms that discrimination against females is deeply ingrained. In other words, women were systematically denigrated as an instrument and this issue is inculcated throughout these textbooks.

The above mentioned issues emphasize that sex bias deep-rooted in these ELT materials in a systematic and organized way. This ingrained systematicity, in which both genders, especially women were depicted along with different trademarks highlight the way by which, sexist attitude is imposed on females. Hence, the gender intolerance is obvious in most parts except the domestic roles and activities, which seem to have nearly equal portions. It is worth mentioning that females and males were not treated fairly even in terms of the activities considered appropriate for them; since the status of activities contributed to each gender differs. In other words, the most passive activities were contributed to women, whereas the most active and high status activities considered appropriate for men. Moreover, the high visibility considered for females vis-à-vis domestic roles imply the point that these textbooks attempt to perpetuate some stereotypes in dealing with the females, for instance the one that states the females' main role is bound indoor activities as mother, sister, wife, housewife, etc. Accordingly, these textbooks are perpetuating the stereotypes, too.

Riches (1999) argues that international ELT publishers-U.S. and Britain as the main publishers of these textbooks - perpetuate the ideology of the late twentieth century capitalist economy. In fact, they claim that ELT industries play an integral role as well as an instrument for realizing the purposes of capitalist economy. Hence, the results obtained from investigating American Headway Series suggest that the authors of this series try to convey values and qualities defined in capitalist economy and modern world of North American Culture regarding females and males. In effect, the series depicted both females and males in association with trademarks as Nestle KitKat, Starbucks Coffee, Cannons Health Club, AAA Insurance Agency, B \& B Vacancies, A-1 Self Storage, American Liberty Mortgage \& Loan Corporation, Rocky's Ace Hardware, Fender Menders, Coca-Cola, McDonald's Hamburgers, a few among others. Hence, these issues lead us to the conclusion that prejudices against women have taken a modern form, while the essence of sexism is still prolonged.

Put it differently, the position that the series considered for both genders especially the females is within market economy. Accordingly, the sexist attitude in this series displayed two forms: in the first one, there is a systematic, continuous and consistent bias in representing the both genders; and in the second one that is dominated by almost all international ELT textbooks, values of the market place were exhibited. In effect, the gender intolerance imposed against females is not only providing inequality in the favor of males, but also imposing more oppression against women in which females were used as an instrument for realizing the purposes of the capitalist economy. The ideology that leads this series seems to be capitalist oriented. This ideology tries to expand the economic system in which private ownerships, private productions and private benefits are celebrated. Capitalism inculcates the values and norms related to market as supply, demand, price, distribution, and investment by exploiting both genders especially the females.

\section{Conclusions}

It was concluded that American Headway Student textbooks follow a sexism attitude merged with ideology of capitalism economy. Capitalism inculcates the values and norms related to market as supply, demand, price, distribution, investment. Apparently, American Headway Student Books (2, 3 and 4) seek to inculcate a particular way of living to learners in order to make benefits from them. In other words, portraying most females with some trademarks as Nestle Starbucks Coffee, Cannons Health Club, AAA Insurance Agency, B \& B Vacancies, A-1 Self Storage, American Liberty Mortgage \& Loan Corporation, Rocky's Ace Hardware, Fender Menders, Coca-Cola, McDonald's Hamburgers a few among others, leads us to this conclusion that prejudices against women have taken a modern form, while the essence of sexism is still prolonged. 
Language and gender: A critical discourse analysis on gender representation in a series of ELT textbooks

Consequently, American Headway Series as internationally distributed ELT textbooks pursues the ideology of the late twentieth century known as capitalist economy. It seems that this series consciously presents both genders in such a way by which stereotypical norms are ingrained into learners. Furthermore, these textbooks adopted the discourse of marketing and advertising by exploiting both genders, especially the females. In fact, this ideology seeks to discover and create new markets, and one of these markets is by international distributed ELT textbooks. Hence, the findings of the present study resulted into the 'hidden curriculum', which was discussed by Skelton (1976) as a curriculum, which is covertly imposed, on the students.

\subsection{Pedagogical Implications}

This study as many other studies have some pedagogical implications for language teachers as well as language learners. It is highly recommended that language teachers adopt a critical perspective regarding the sociolinguistic issues in which only an angle of the events is explained. In fact, teachers need to create a focus group in which students and teacher discuss the gender-related issues represented in the textbooks exposed to them. Furthermore, this study insists that teachers develop their professional expertise through reflecting and exploring the textbooks that they teach to the students along with the different events which happen in the classroom with a critical perspective. There is no doubt that the findings of this study have also pedagogical implications for textbooks designers, since textbooks play a significant role in teaching language to the students. This issue implies that textbooks' designers should consider gender biases, which are depicted in the ELT textbooks, which may impair the learning abilities of the students (Rifkin, 1998). The fact should not be ignored that the educational programs need to equip the teachers with the strategies to be able to deal with the shortcomings and ideologies behind gender representation in ELT materials to mollify the gender role on the learning capabilities of the students.

\section{References}

Bell, M., McCarthy, M., \& McNamara, S. (2006). Variations in language use across gender. Retrieved from http://csep.psyc.memphis.edu/mcnamara/pdf/Bellgender28CogSci.pdf

Chouliaraki, L., \& Fairclough, N. (1999). Rethinking critical discourse analysis. Edinburgh: Edinburgh University Press.

Esmaili, F., \& Amerian, M. (2013). Gender representation in Iranian High School English Textbooks with a critical discourse analysis perspective. International Journal of Language Learning and Applied Linguistics World, 5(4), 277-289.

Fairclough, N. (1989). Language and power. London: Longman.

Fairclough, N. (2001). Language and power (2nd ed.). Harlow: Pearson Education.

Fowler, R., \& Kress, G. (1979). Critical linguistics. In R. Fowler, B. Hodge, G. Kress, \& T. Trew (Eds.), Language and control (pp. 185-213). London: Rutledge and Keegan Paul.

Gershuny, H. L. (1977). Sexism in dictionaries and texts: Omissions and commissions. In A. P., Nilsen, H. Bosinajian, H. L. Gershuny, \& J. P. Stanley (Eds.), Sexism and language (pp. 161-179). Illinois: National Council of Teachers of English.

Ho, W. L. (2009). Is women or liquor being sold. Retrieved from www.hku.hk/english/LCOM\%20paper/...\%20rev/.../3_Vienna_Ho.pdf

Keshavarz, M. H., \& Malek, L. A. (2009). Critical discourse analysis of ELT textbooks. The Iranian EFL Journal, 5, 6-15.

Key, M. R. (1975). Male/female language. Metuchen, NJ: The Scarecrow Press.

Lakoff, R. (1975). Language and women's place. New York: Harper and Row.

Lee, J. F. K. (2006). Gender representation in Hong Kong English textbooks. Retrieved from http://www.eoc.org.hk/eoc/upload/2006711112336211184.pdf

Meyer, M. (2001). Between theory, method and politics: Positioning of the approaches to CDA. In R. Wodak \& M. Meyer (Eds.), Methods of critical discourse analysis (pp. 14-31). London: Sage Publications. 
Amerian, M., \& Esmaili, F.

Rahimi, A., \& Sahragard, R. (2007). Critical discourse analysis. Tehran: Jungle Publications.

Riches, D. (1999). Problems of content specificity in ELT textbooks: A critical discourse analysis study of ELT textbooks. Retrieved from http://www.linkedin.com/pub/dennis-riches/11/454/919.html

Rifkin, B. (1998). Gender representation in foreign language textbooks: A case study of textbooks of Russian.

The Modern Language Journal, 82, 217-236. http://dx.doi.org/10.1111/j.1540-4781.1998.tb01195.x

Skelton, A. (1997). Studying hidden curricula: Developing a perspective in the light of postmodern insights.

Curriculum Studies, 5, 177- 93.

Soars, J., \& Soars, L. (2001). American Headway 2 (student book). New York: Oxford University Press.

Soars, J., \& Soars, L. (2003). American Headway 3 (student book). New York: Oxford University Press.

Soars, J., \& Soars, L. (2005). American Headway 4 (student book). New York: Oxford University Press.

Stockdale, A. D. (2006). Gender representation in an EFL textbook. Unpublished master's thesis, University of

Birmingham, UK. Retrieved from

http://www.cels.bham.ac.uk/resources/essays/DAStockdale-Sociolinguistics.pdf

Tahriri, A. B., \& Moradpour, P. (2014). Gender representation in 'Top-Notch' series: A critical discourse analysis perspective. International Journal of Research Studies in Psychology, 3(2), 39-51. http://dx.doi.org/10.5861/ijrsp.2014.633

Thorne, B., \& Henely, N. (1975). Language and sex: Difference and dominance. Rowley, MA: Newbury House.

Weiss, G., \& Wodak, R. (2003). Critical discourse analysis: Theory and interdisciplinarity. New York: Palgrave Macmillan.

Wodak, R. (2001). What CDA is about-a summary of its history, important concepts and its developments. In R. Wodak, \& M. Meyer (Eds.) Methods of critical discourse analysis (pp. 1-13). London: Sage Publications.

Wodak, R. (2002). Aspects of critical discourse analysis. The Zeitschrift für Angewandte Linguistik, 36, 5-31.

Wodak, R. (2007). Pragmatics and critical discourse analysis. Retrieved from http://www.essex.ac.uk/centres/TheoStud/pragmcognitionwodak2007.pdf 